\title{
Optimization of process parameters for surface roughness of Inconel 625 in Wire EDM by using Taguchi method
}

\author{
Pradeep Kumar Karsh ${ }^{1}$, Hari Singh ${ }^{2}$ \\ ${ }^{1}$ (M.Tech Scholar, National Institute of Technology Kurukshetra, Haryana) \\ ${ }_{2}^{2}$ (Professor, National Institute of Technology Kurukshetra, Haryana)
}

\begin{abstract}
WEDM is the widely adopted non convectional machining process which is mainly used for machining very hard and tough material like super alloys. Application of WEDM is mostly found in aerospace, die making etc. industries due to high accuracy and precision work. Inconel is mainly a super alloy which is mixture of nickel and chromium, which is very high melting point and strength. Due to these properties Inconel is mainly machined by WEDM. In this paper attempt was made to optimize the different process parameters like pulse on time, pulse off time and peak current for the surface roughness. Taguchi L9 orthogonal array along with ANOVA is used for optimize the different parameters so that minimum surface roughness obtained. From the experiment results found that pulse on time is the most significant factor (contributing $92.35 \%$ ) and peak current is an insignificant factor. At the end, confirmation test have conducted to verify the results.
\end{abstract}

Keyword: WEDM, Inconel 625, Taguchi method, ANOVA, Optimization

\section{INTRODUCTION}

Inconel 625 is super alloy of nickel and chromium which is mainly used in gas turbine blades, high temperature fasteners, heat exchanger tubing, seals, combustors, steam generators as well as turbocharger rotors and seals due to its superiority mechanical and thermal properties. These super alloys are facing very difficulties for machining with convectional machining due to limitation of temperature developed in machining. To machining these super alloys non convectional machining such as electro chemical machining, electric discharge machining, ultrasonic machining etc. are used because these are capable to machining with high accuracy and excellent finishing. Wire EDM is the advancement of EDM in which wire is used as electrode [1]. WEDM is an electrothermal machining in which a series of spark is produced between the electrode (wire) and work piece which is submerged in the dielectric fluid. During the pulse-on time or discharge period, work material is rapidly melted and vaporized to form a cut on the workpiecewhich is flashed by the dielectric fluid. Dielectric is used to cooling the cutting zone and to remove the debris from the cutting zone to ready for the next pulse discharge [2]. Electrode wire is made of brass, copper or zinc coated which have good electrical conductivity with diameter of $0.25 \mathrm{~mm}$. In wire EDM there is no direct contact between the work piece and electrode so that there is no mechanical stress development. The schematic diagram of WEDM is shown in figure 1.

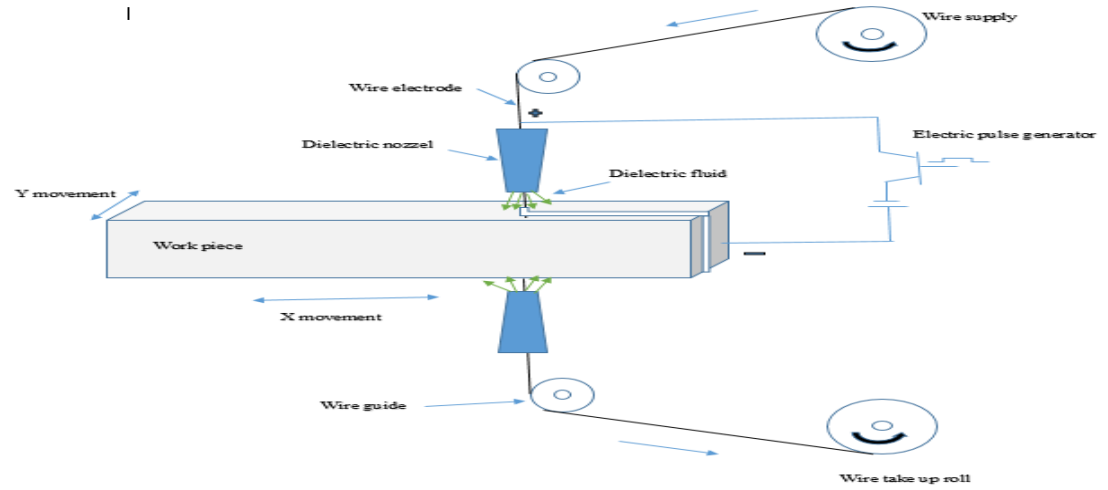

Fig. 1: Representation of WEDM process 
Several researchers have attempted to optimize the different responses such as MRR, SR and Dimensional deviation. Ikram et al. used Taguchi design of experiment to optimize the surface roughness, kerf and MRR for tool steel D2. They take wire feed velocity, pulse on-time, pulse off-time, dielectric pressure, open voltage, servo voltage and wire tension as input parameter. They found that for surface roughness pulse on time and open voltage as most significant factor. Pulse on-time, wire tension and open voltage are more the significant factors for kerf [3].Han et al. determine the influence of the machining parameters (including discharge current, pulse duration, pulse interval time, sustained pulse time, polarity effect, dielectric and material) on surface roughness. They found that the surface roughness increased by decreasing both pulse duration and discharge current. They suggest that a short pulse duration combined along with a high peak value gives better surface roughness [4].Ugrasen et al. used Taguchi method along with the artificial neural network to optimize the accuracy, surface roughness and MRR. They found that for the above three responses, current is the most significant factor. They used Back propagation feed forward neural network along with Levenberg-Marquardt algorithm to build and train the network [5].Sudhakara and Prasanthi used Taguchi $\mathrm{L}_{27}$ to optimize the surface roughness of P/M Cold WorkedTool Steel (Vanadis-4E). They found the range optimal setting of different parameters as pulse on time $=108-128 \mu \mathrm{sec}$, pulse off time $=47-63$ $\mu$ sec, peak current $=11-13$ Amperes, spark gap set voltage $=18-68$ Volts, wire tension $=2-8$ Grams and water pressure $=8-14 \mathrm{Kg} / \mathrm{cm}^{2}[6] . \mathrm{K}$. Kumar et al. did modelling and optimization of WEDM for surface roughness and MRR in Al-SIC. They used RSM along with Taguchi's L27 OA. They found that factors like speed, feed, Time on and Time off most significant factor for MRR and surface roughness [7].Antar et al. tried to found the fatigue behavior of Udimet 720 nickel based super alloy by using the minimum damage generator technology in wire EDM. They did comparative study between the wire EDM job and flank milled samples by using $\mathrm{S}-\mathrm{N}$ curve. They conclude that at the room temperature no significant difference in fatigue life of WEDM and flank milled samples of Udimet 720 alloy [8].Kanlayasiri and Jattakul found the optimal cutting condition of dimensional accuracy and surface roughness for K460 tool steel by wire EDM machine. They used Box- Behnken design and multiple response optimization technique. They also considered cutting speed, peak current, and offset distance as input variable and dimensional accuracy and surface roughness as output variables. They found that both peak currentandoffset distance is significant factor for dimension while peak current affects the surface roughness. The optimal condition for cutting was at 2 A peak current and $772 \mu \mathrm{m}$ offsetdistance [9]. Sharma et al. found the MRR, SR, recast layer, topography, micro hardness of Inconel 706 for turbine disk application. The proposed experimental plan was based on OFAT approach. The micro hardness and RLT have been examined using the low and high settings of servo voltage and pulse on time. EDAX analysis has been carried out to study the metallurgical changes in the machined surface. They found that pulse on time, pulse off time and servo voltage are most important factors, whereas servo feed is not important. They also found that wire feed of $6 \mathrm{~m} / \mathrm{min}$ and flushing pressure of $1.96 \mathrm{bar}$ gives higher MRR and SR [10]. Raoand Venkaiah hadattempt to found the effect of different parameters on MRR and SR of Nimonic-263 alloy. RSM and ANOVA are used for experiment and estimation. They developed mathematical model for MRR and SR by using RSM. They also optimize the performance of process by using Particle Swarm Optimization (PSO). They also compare the results obtained from the RSM and PSO. They found that PSO is better than RSM. They take Pon, Poff, SV and IP as input parameters. They found that for MRR, pulse on time, peak current and interactions of these are more important factors. For SR, servo voltage, pulse on time, pulse off time and interaction of Pon andPff play an important factor [11]. Ugrasen et al. in 2014 used Multiple Regression Analysis (MRA), Group Method Data Handling Technique (GMDH) and Artificial Neural Network (ANN) to forecasting effect of process variable on the process response in wire EDM [12]. Md.karimBaig et al. optimize the process parameters of wire EDM for HastelloyC276 by using the Taguchi and Grey Relational Analysis. MRR and Kerf width are taken as response variable. They found that for MRR and Kerf Width, discharge current (IP) is more important factor. 2 A discharge current is optimum condition for higher MRR and lower Kerf Width. The next parameters that are found to be effective are Servo voltage (SV), Pulse on time (TON), Pulse off time (TOFF) in that order. Grey Relational Analysis (GRA), for finding the optimal parameters affecting both MRR and Kerf are found to be TON $=110 \mu \mathrm{s}$, TOFF $=60 \mu \mathrm{s}, \mathrm{IP}=12 \mathrm{~A}, \mathrm{SV}=10 \mathrm{~V}$, for both higher MRR value of 11.78 $\mathrm{mm}^{3} / \mathrm{min}$ and lower Kerf a value of $0.375 \mathrm{~mm}$ [13].E. Atzeni et al.used zinc coated brass wire for cutting of Inconel 718 to optimize the process parameters and obtaining modification in the surface and sub surface. SEM and EDS were used to evaluate possible variation in the surface chemical composition [14]. 


\section{EXPERIMENTAL DETAIL}

$2.1 \quad$ Theme of experiment

In this paper an attempt have made to optimize the cutting contidions to minimize the surface roughness based on the Taguchi method. WEDM involves many process parameters like pulse on time, pulse off time, peak current, servo voltage, wire feed rate, wire tension, dielectric pressure etc. In this paper only consider first three parameters as mentioned above.

- Pulse on time - The time for which current is applied is called pulse on time, denoted as Ton in micro second $(\mu \mathrm{s})$.

- Pulse off time - The duration time between the two simultaneous sparks is known as the pulse off time denoted as Toff in $(\mu \mathrm{s})$. No voltage is applied during this time.

- Peak Current - It is the maximum value of the current passing through the electrodes for the given pulse and represented by IP.

\subsection{Experimental setup}

Experiment were performed on a wire-cut EDM machine with specification like design fixed column, moving table type with size of the work piece 440 x $650 \mathrm{~mm}$, type of interpolation linear \& circular, power supply 3 phase, AC $415 \mathrm{~V}, 50 \mathrm{~Hz}$. Inconel 625 is taken as work material of size $80 * 80 * 14 \mathrm{~mm}$ plate. Wire diameter $0.25 \mathrm{~mm}$ made of copper is used for experiment. Wire is tensioned between upper and lower guide to obtained higher accuracy. Deionized water is taken as the dielectric fluid with 12 to 16 TDS (total dissolved solid). Surface roughness tester is used to measure surface roughness as shown in figure 2.

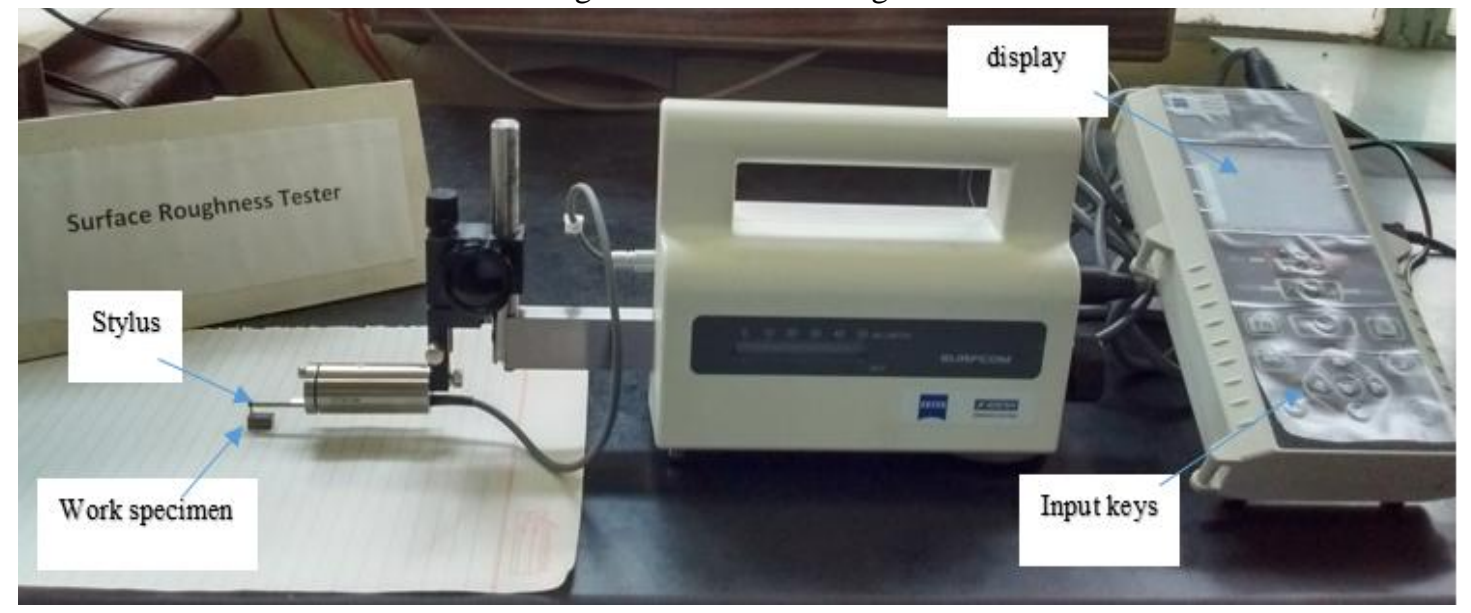

Fig. 2: Roughness Tester [Courtesy: NIT KKR]

\subsection{Experimental design}

Taguchi method with L9 orthogonal array and ANOVA is used for this study. Taguchi method is applied were reduce the number of trial so that cost and time minimized. In Taguchi method only perform few experiments instead of all possible setting of experiments which required in full factorial design. Each parameters at three levels are selected. The levels are taken from the previous study of literature review. The levels of selected parameters are shown in table 1.

TABLE I. Process parameters and their levels

\begin{tabular}{|c|c|c|c|c|}
\hline \multirow{2}{*}{ Factors } & Parameters & \multicolumn{3}{|c|}{ Levels } \\
\cline { 3 - 5 } & & L1 & L2 & L3 \\
\hline A & Pulse on Time $(\mu \mathrm{s})$ & 105 & 115 & 125 \\
\hline B & Pulse off Time $(\mu \mathrm{s})$ & 35 & 45 & 55 \\
\hline C & Peak current $(\mathrm{A})$ & 120 & 140 & 160 \\
\hline
\end{tabular}




\section{Result and Discussion}

The WEDM experiments were conducted to study the effect of process parameters over surface roughness. The values surface roughness obtained from the roughness tester is shown in Table 2 .

TABLE II. Reading obtained from surface roughness tester

\begin{tabular}{|c|c|c|c|c|c|}
\hline $\begin{array}{c}\text { Exp. } \\
\text { No. }\end{array}$ & $\begin{array}{c}\text { Factor A } \\
\text { Ton }\end{array}$ & $\begin{array}{c}\text { Factor B } \\
\text { Toff }\end{array}$ & $\begin{array}{c}\text { Factor C } \\
\text { IP }\end{array}$ & $\begin{array}{c}\text { Surface } \\
\text { roughness }(\boldsymbol{\mu m})\end{array}$ & S/N ratio \\
\hline 1 & 105 & 35 & 120 & 3.263 & -10.2723 \\
\hline 2 & 105 & 45 & 140 & 2.751 & -8.7898 \\
\hline 3 & 105 & 55 & 160 & 1.630 & -4.2438 \\
\hline 4 & 115 & 35 & 140 & 6.223 & -15.8800 \\
\hline 5 & 115 & 45 & 160 & 5.980 & -15.5340 \\
\hline 6 & 115 & 55 & 120 & 5.306 & -14.4953 \\
\hline 7 & 125 & 35 & 160 & 7.335 & -17.3080 \\
\hline 8 & 125 & 45 & 120 & 7.047 & -16.9601 \\
\hline 9 & 125 & 55 & 140 & 6.696 & -16.5163 \\
\hline
\end{tabular}

It is observed that from the figure 3 (obtained from MINITAB software) when pulse on time increase surface roughness also increases. This is due to increase in the discharge energy with increase in pulse on time so more strong explosion and the deeper crater created on the machined surface resulting rougher surface. It is found that with increase in pulse off time surface roughness decreases and peak current have no longer effect on the surface roughness.

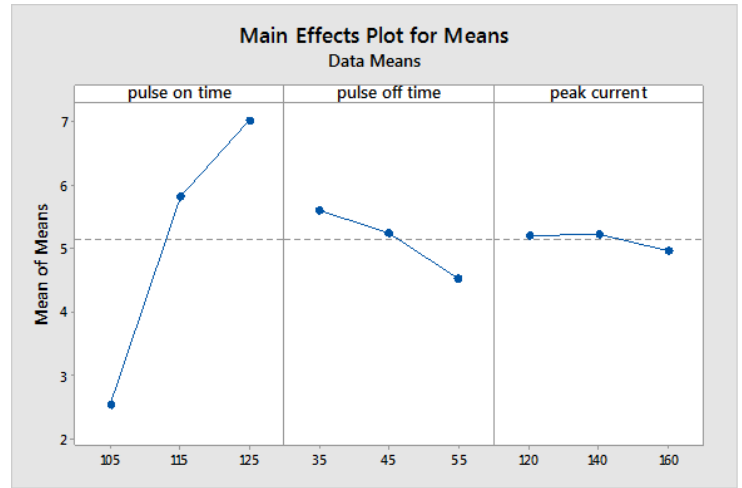

TABLE III. Pooled ANOVA

Fig. 3: Main effect plot for Mean (Surface roughness)

To determine the significant parameters affecting the surface roughness Analysis of variance (ANOVA) was performed. In the present investigation, $90 \%$ confidence level or $10 \%$ level of significance is taken. From the ANOVA it is found that peak current is insignificant factor so that it is pooled shown in table 3.It is found that pulse on time is most significant factor (contributing $92.35 \%$ ) followed by pulse off time (3.406\%). Surface roughness is the "lower the better characteristics" so pulse on time at first level $\left(\mathrm{A}_{1}\right)$ and pulse off time at third level $\left(\mathrm{B}_{3}\right)$ gives the optimum condition i.e. minimum surface roughness. Fig. 4 shows percentage contribution of different process variable on the surface roughness. The predicated optimal value at significant factors is calculated as follows:

$\mu=\overline{\mathrm{A}}_{1}+\overline{\mathrm{B}}_{3}-\overline{\mathrm{T}} \quad=2.548+4.544-(5.136) \quad=1.956$

$\mathrm{CI}_{\mathrm{POP}}= \pm\left[\mathrm{F} \alpha\left(\mathrm{n}, \mathrm{f}_{\mathrm{e}}\right) * \mathrm{~V}_{\mathrm{e}} / \mathrm{n}_{\mathrm{eff}}\right]^{1 / 2}= \pm[4.32 *(0.2011 / 1.8)]= \pm 0.4826$

Where, $F \alpha\left(n, f_{e}\right)=4.32, V_{e}=0.2011, n_{\text {eff }}=9 /(1+4)=2$ 
Optimum value $=1.956 \pm 0.4826$

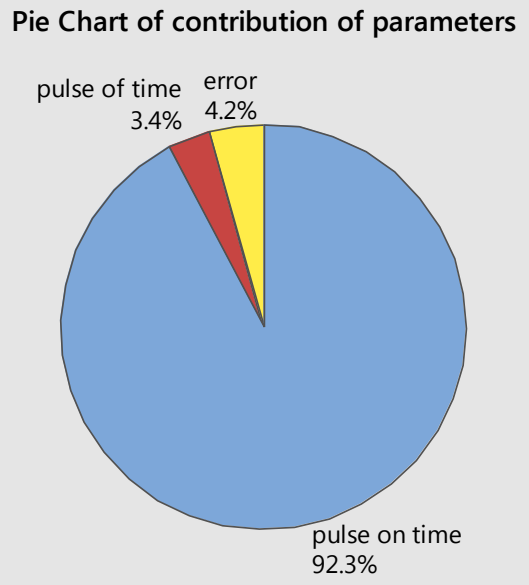

Fig. 4: Percentage contribution of process variables

IV.

CONFIRMATION TEST

After successful applying the Taguchi method along with ANOVA it is found that the optimal setting of the process parameters as first level of pulse on and third level of pulse off time. To validate the result obtained perform the confirmation experiment and results obtained from confirmation test is shown in table 4.

TABLE IV. Confirmation Results

\begin{tabular}{|c|c|c|c|}
\hline Machining characteristics & $\begin{array}{c}\text { Optimal setting of } \\
\text { parameters }\end{array}$ & $\begin{array}{c}\text { Predicted value by } \\
\text { Taguchi method }\end{array}$ & $\begin{array}{c}\text { Results obtained from } \\
\text { confirmation experiment } \\
\mathbf{A}_{\mathbf{1}} \mathbf{B}_{\mathbf{3}}\end{array}$ \\
\hline Surface roughness & $\mathrm{A}_{1} \mathrm{~B}_{3}$ & $1.956 \pm 0.4826$ & $1.85 \mu \mathrm{m}$ \\
\hline
\end{tabular}

\section{CONCLUSION}

In this experiment optimization of process parameters for surface roughness in Inconel 625 was carried out. The machining parameters are pulse on time, pulse off time and peak current. After successful application of Taguchi method and ANOVA it is conclude the following:

1. Surface roughness increases with increase on pulse on time and decrease with increase in pulse off time.

2. For surface roughness most significant factor is pulse on time (contributing $92.35 \%$ ) followed by pulse off time.

3. Peak current is insignificant factor for surface roughness.

4. Optimal setting for surface roughness is $A_{1} B_{3} C_{3}$ which gives minimum surface roughness value.

\section{REFERENCES}

[1] K. Kanlayasiri and S. Boonmung "Effects of wire-EDM machining variables on surface roughness of newly developed DC 53 die steel: Design of experiments and regression model" Journal of Materials Processing Technology 192-193 (2007) 459-464

[2] JirapornPunturat, ViboonTangwarodomnukun and ChaiyaDumkum" Surface characteristics and Damage of monocrystalline silicon induced by wire-EDM" Applied Surface Science 320 (2014) 83-92

[3] Adeellkram, Ahmad Mufti, Saleem and Ahmed Raza Khan "Parametric optimization for surface roughness, kerf and MRR in wire electrical discharge machining (WEDM) using Taguchi design of experiment” Journal of Mechanical Science and Technology 27 (7) (2013) 2133 2141 
[4] Fuzhu Han, Jun Jiang \&Dingwen Yu "Influence of machining parameters on surface roughness in finish cut of WEDM" International Journal of Advance Manufacturing Technology (2007) 34:538-546

[5] G.Ugrasen, H.V.Ravindra, Naveen Prakash and R.Keshavamurthy "Process optimization and estimation of machining performances using artificial neural network in wire EDM" Procedia Materials Science 6 (2014)1752 - 1760

[6] D.Sudhakara and G.Prasanthi "Application of Taguchi Method for Determining Optimum Surface Roughness in Wire Electric Discharge Machining of P/M Cold Worked Tool Steel (Vanadis-4E)" Procedia Engineering 97 (2014) 1565 - 1576

[7] K. Kumar and R. Ravikumar "Modeling and Optimization of Wire EDM Process" International Journal of Modern Engineering Research (IJMER) Vol. 3, Issue. 3, May.-June. 2013 pp-1645-1648

[8] M.T. Antar, Soo, Aspinwall, C. Sage, Cuttell, Perez and A.J. Winn "Fatigue response of Udimet 720 following minimum damage wire electrical discharge machining" Materials and Design 42 (2012) 295-300

[9] KannachaiKanlayasiri and PrajakJattakul "Simultaneous optimization of dimensional accuracy and surface roughness for finishing cut of wire-EDMed K460 tool steel" Precision Engineering 37 (2013) 556- 561

[10] Priyaranjan Sharma, D. Chakradhar and S. Narendranath "Evaluation of WEDM performance characteristics of Inconel 706 for turbine disk application" Materials and Design 88 (2015) 558-566

[11] SreenivasaRao and N. Venkaiah "Parametric optimization in machining of Nimonic-263 alloy using RSM and particle swarm optimization" Procedia Materials Science 10 (2015) 70 - 79

[12] G.Ugrasen, ravindra, N.prakash and Keshavamurthy "Estimation of machining performances using MRA, GMDH and Artificial Neural Network in Wire EDM of EN-31" Procedia Materials Science 6 ( 2014 ) 1788 - 1797

[13] Md.karimBaig et al. "Parametric optimization of WEDM for HastelloyC276, using GRA method" International Journal of Engineering Development and Research ISSN: 2321-9939

[14] E. Atzeni, Bassoli, Gatto, Iuliano, Minetola and Salmi, "Surface and sub surface evaluation in coated wire electric discharge machining of Inconel alloy 718” Procedia CIRP 33, 389 - 394 (2015) 